\title{
Chapter
}

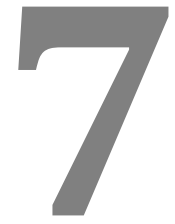

\section{CERAGENINS AS NON-PEPTIDE MIMICS OF ENDOGENOUS ANTIMICROBIAL PEPTIDES}

\section{Marjan M. Hashemi, Brett S. Holden, and Paul B. Savage*}

Department of Chemistry and Biochemistry, Brigham Young University, Provo, UT, USA 


\section{Contents}

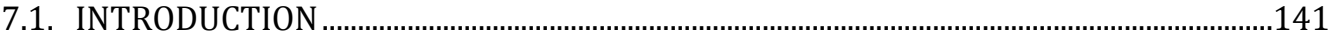

7.2. ANTIMICROBIAL PEPTIDES: DEFINITION, SOURCE AND HISTORY .................................141

7.3. STRUCTURE AND MECHANISM OF ACTION OF AMPS............................................................142

7.4. DESIGN OF CERAGENINS.......................................................................................................144

7.5. MECHANISM OF ACTION OF CERAGENINS............................................................................145

7.6. ANTIMICROBIAL SPECTRUM OF ACTIVITY OF CERAGENINS............................................147

7.6.1. Antibacterial activity .............................................................................................147

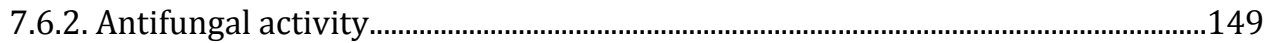

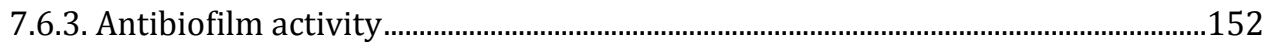

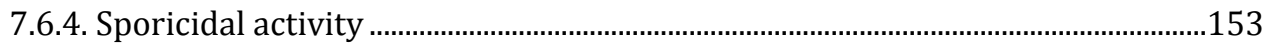

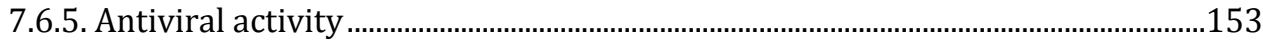

7.6.6. Anti-parasite activity .............................................................................................153

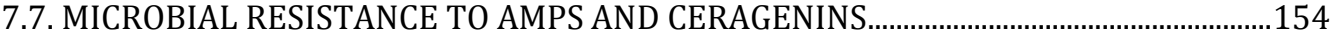

7.8. EFFECT OF POLOXAMER MICELLES ON THE ANTIMICROBIAL ACTIVITIES AND CYTOTOXICITY OF CERAGENINS..........................................................................................158

7.9. NANOPARTICLES AS CARRIERS OF CERAGENINS.................................................................159

7.10. MEDICAL APPLICATIONS OF CERAGENINS .........................................................................161

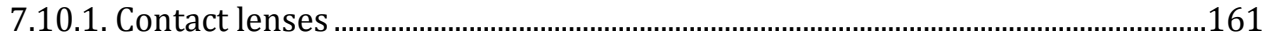

7.10.2. Implanted medical device coatings ...........................................................................

7.10.3. Coated endotracheal tubes...................................................................................164

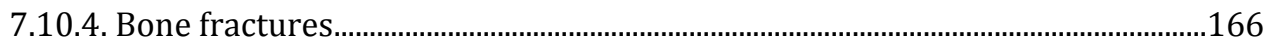

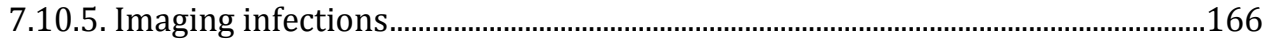

7.10.6. Gastrointestinal diseases ..........................................................................................167

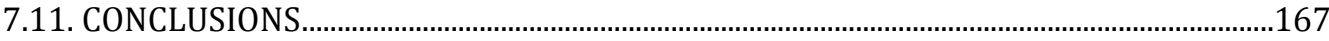

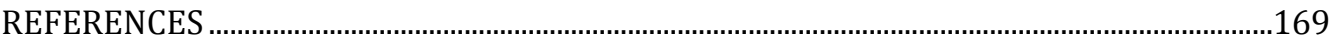




\subsection{INTRODUCTION}

Antimicrobial peptides (AMPs) are evolutionarily-conserved molecules that are produced as a first line of defense by organisms ranging from prokaryotes to humans. In higher organisms, they are naturally found in the skin, airways, gastrointestinal tract and reproductive tracts with the highest concentrations of AMPs being found in the tissues that are regularly exposed to pathogens. They display broad-spectrum activity against bacteria, fungi, lipid-enveloped viruses and parasites. In higher organisms, AMPs exert additional immunomodulatory activities such as anti-inflammatory properties, through sequestration of bacterial endotoxins, and acceleration of wound healing by promotion of cell migration into wound beds and neovascularization. Common features of AMPs are juxtaposed cationic amino acids and hydrophobic residues on opposing faces of helices or sheets. This morphology provides them with a unique amphiphilic structure that selectively associates with microbial membranes, disrupts membrane integrity, and leads to cell death.

Despite the broad-spectrum antimicrobial activities of AMPs and the belief that microorganisms are unlikely to become resistant to AMPs, their clinical application is limited due to the high cost of production and their degradation by bacterial proteases. In order to overcome these clinical challenges, ceragenins were developed as non-peptide mimics of AMPs. They are based on a common bile acid and mimic the amphiphilic morphology of AMPs with a similar spectrum of activity against bacteria, fungi and lipid-enveloped viruses. Straightforward preparation of ceragenins and their stability in the presence of proteases paves the way for large-scale production and clinical application. This chapter will discuss the development of ceragenins, their breadth of antimicrobial activities, impacts on innate immune functions and wound healing, and specific applications of ceragenins as stand-alone antimicrobial agents and in medical device coatings.

\subsection{ANTIMICROBIAL PEPTIDES: DEFINITION, SOURCE AND HISTORY}

AMPs are evolutionarily conserved molecules that exist in organisms ranging from prokaryotes to humans as a first line of defense [1,2]. They are naturally found in the skin, airways, gastrointestinal tract, and urinary and reproductive tracts with the highest concentrations of AMPs being found in the tissues that are exposed to pathogens $[3,4]$. The first human AMP described, lysozyme, was discovered in 1922 by Alexander Fleming from his own nasal mucus. Further investigation demonstrated that lysozyme targets bacteria by hydrolyzing the 
linkage of peptidoglycan of the cell wall in Gram-positive bacteria [5-8]. However, antimicrobial use of lysozyme was overshadowed by the discovery of penicillin in 1928, also by Fleming [9]. The emergence of drug-resistant pathogens in the 1960s brought the potential of therapeutic use of AMPs again to the attention of scientists. Pioneering work in 1956 resulted in discovery of defensins, the first animal-originated AMPs, isolated from rabbit leukocytes [10]. This was followed by the report of lactoferrin from milk in the 1960s [11]. Cecropin, first isolated from the Cecropia silk moth Hyalophora cecropia in 1981, was the first helical AMP reported [12,13]. Zasloff and colleagues isolated magainins from the skin of the African clawed frog Xenopus laevis in 1987 and found that it displayed broad spectrum antimicrobial activity [14]. It is also worth noting that prokaryotes produce and release AMPs to fight other microorganisms in their environment; however, these AMPs mostly have cyclic or branched structures. These AMPs are often synthesized by a non-ribosomal peptide synthase through a specialized metabolic pathway, unlike eukaryotic AMPs which are synthesized by the ribosome. To date, over 250 of these bacteriocins have been identified from bacteria [9]. Of particular interest are the commercial antibiotics polymyxin B (cationic) and vancomycin (noncationic), which are isolated from Bacillus polymyxa and Amycolatopsis orientalis, respectively. Polymyxin B displays potent antibacterial activity against Gram-negative bacteria and vancomycin against Gram-positive bacteria $[15,16]$.

\subsection{STRUCTURE AND MECHANISM OF ACTION OF AMPS}

AMPs mainly fall into three classes: $\alpha$-helical, $\beta$-sheet, and extended, depending on their secondary structures $[17,18]$. Magainins and the human cathelicidin LL37 (hereafter LL-37) are prominent examples of AMPs with substantial $\alpha$-helical structure $[19,20]$. $\beta$-sheet AMPs include defensins and feature disulfide bond that stabilize their structure [21]. AMPs derived predominantly from one type of amino acid are categorized as extended AMPs and include human histatins, which are rich in histidine, and bovine indolicidin, which is rich in tryptophan and arginine [22].

Nearly all AMPs are amphipathic, meaning they have both cationic and hydrophobic character. However, unlike typical surfactants, with polar head groups and hydrophobic tails, AMPs display polar, cationic functionality on one face of the molecule with hydrophobic groups juxtaposed on the opposite face [23]. Defensins and cathelicidins constitute the major families of membraneactive AMPs in vertebrates [24]. And with these AMPs, an initial, selective electrostatic interaction between the positive charges on one face of the AMPs and negative charges of membranes occurs. Due to their facial amphiphilicity, the hydrophobic domains of AMPs cannot stably insert into intact membranes, 
and at sufficient local concentrations, AMPs cause membrane perturbation leading to a loss of polarization, resulting in cell death. Membrane composition allowing selective association of AMPs with microbial membranes, plays a key role in cell selectivity [25]. For example, magainins show higher affinity for anionic phospholipids, which are highly represented in bacterial membranes. Cell membranes of higher organisms, however, feature neutral phospholipids and cholesterol, which diminish AMP interactions [26,27]. For this reason, much higher concentrations of AMPs are required to kill cells from higher organisms as compared to microbial cells. Targeting of the cell membranes by AMPs gives rise to their breadth of spectrum of activity: bactericidal activity against Gram-negative and positive bacteria, antifungal activity and even activity against lipid-enveloped viruses. This breadth of activity may offer advantages over antibiotics that target specific cellular processes, such as DNA and protein synthesis, leading to narrow spectra of activity. Membranetargeting properties of AMPs contribute to the rapid antimicrobial activity, with some AMPs able to kill microorganisms with only seconds of exposure $[13,28]$.

In higher eukaryotic organisms, AMPs display immunomodulatory activities [29], including anti-inflammatory properties through the sequestration of bacterial endotoxins such as lipopolysaccharide (LPS). In addition, multiple studies support the idea that human AMPs improve wound healing via promotion of cell migration into wound beds, angiogenesis, and neovascularization [30]. AMPs are generally constitutively expressed in healthy epithelium, and their production is upregulated in response to injury or infection to moderate microbial proliferation and signal host cells to activate secondary immunomodulatory roles. For example, a study with a human skin wound healing model, LL-37 was expressed acutely post-injury, whereas its concentration was reduced in chronic ulcer epithelium where reepithelization is impaired, suggesting that LL-37 plays a prominent role in wound closure [31].

Despite the broad-spectrum antimicrobial activities of AMPs and their woundhealing and immunomodulatory properties, there are factors that limit their clinical applications. These include their susceptibility to proteases released by bacteria, the high cost of producing them on a large scale, decreased activity when immobilized, and folding problems in the production of some large AMPs [13].

We developed ceragenins as non-peptide mimics of AMPs [32]. They are synthesized from cholic acid, a common bile acid, in few synthetic steps (Figure 1) [33-36]. Due to the fact that they are not peptide-based, they are not substrates for ubiquitous proteases. Preparation and purification of ceragenins on a large scale is relatively straightforward, they are stable under physiological conditions and even long-term storage in solution does not reduce their antibiotic activities [37,38]. As ceragenins follow the amphiphilic 
structure of AMPs they display a similar spectrum of activity against bacterial, fungi and lipid-enveloped viruses [39].

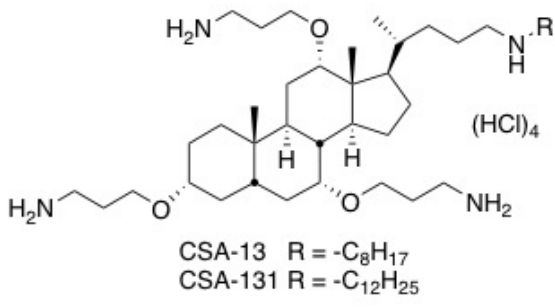

Figure 1. Structures of selected ceragenins CSA-13, CSA-131, CSA-142, CSA-44 and CSA-144

\subsection{DESIGN OF CERAGENINS}

Preliminary design of the ceragenins (examples in Figure 1) was based on the presumed lipid A binding domain of polymyxin B. The primary amines from diaminobutyric acid groups in polymyxin B are oriented on one face of the molecule, and to mimic this arrangement, three primary amines were tethered to cholic acid to generate similar amine spacing in ceragenins. Tether lengths were incrementally varied to determine the optimal spacing between the steroid backbone and the amine groups [40-43]. These initial attempts to mimic the structure of polymyxin B resulted in preparation of ceragenins with activity against Eschericia coli [minimal inhibitory concentration (MIC) range 2.0-46 $\mu \mathrm{g} \mathrm{mL}^{-1}$ ]. A truncated form of polymyxin B, polymyxin B nonapeptide, permeabilizes the outer membranes of Gram-negative bacteria, sensitizing them to hydrophobic antibiotics. With the initial series of ceragenins, this type of sensitization was observed with erythromycin against $E$. coli; concentrations of CSA-8 as low as $1 \mu \mathrm{g} \mathrm{mL}-1$ lowered the MIC of erythromycin from 70 to $1 \mu \mathrm{g} \mathrm{mL}^{-1}[40,44]$. Further structure-activity studies demonstrated that the chain extending from the $\mathrm{D}$ ring of the bile acid played a central role in controlling direct antibacterial activity vs. sensitizing activity of Gram-negative bacteria. With lipophilic groups attached to this chain, the resulting ceragenins displayed broad-spectrum antibacterial activity (Gram-negative and -positive). For example, CSA-13 gave an MIC of $3.0 \mu \mathrm{g} \mathrm{mL}-1$ against E. coli (Gram-negative) and $0.40 \mu \mathrm{g} \mathrm{mL}^{-1}$ against Staphylococcus aureus (Gram-positive). Ceragenins lacking lipophilic groups on the D-ring retained antibacterial activity against Gram-positive bacteria but lost substantial activity against Gram-negative bacteria. For example, CSA-8, without an extensive lipid chain, gave an MIC of 
$36 \mu \mathrm{g} \mathrm{mL}^{-1}$ against E. coli, and an MIC of $2.0 \mu \mathrm{g} \mathrm{mL}^{-1}$ against $S$. aureus. Nevertheless, ceragenins lacking lipophilic groups extending from the D ring retained the ability to sensitize Gram-negative bacteria to hydrophobic antibiotics [45].

From these results, we postulated that lipid chains extending from the D ring enabled ceragenins to traverse the outer membrane and exert antibacterial activity through interactions with the cytoplasmic membrane. Gram-positive bacteria lack an outer membrane, and they are susceptible to ceragenins with and without a lipid chain. Ceragenins lacking a lipid chain extending from the D ring remain on the outer surface of the outer membrane, and association of these ceragenins with the lipid A component of the membrane causes perturbations in the membrane that allow hydrophobic antibiotics to traverse the membrane $[35,40,44]$.

Further structure activity studies involved replacement of the ether bonds tethering the amines to the bile acid with amide and ester groups. To use amide groups in the tethers, it was necessary to synthesize a tri-amino version of cholic acid [46]. These amines were functionalized with amino acids, generating amides. The resulting ceragenins displayed antibacterial activity, but less than that of the ceragenins with ether bonds for the tethers. By differentially protecting the three amines in the tri-amino version of cholic acid, it was possible to sequentially incorporate different amino acids at each amine. Although this method of preparing ceragenins resulted in the production of large numbers of compounds, none were as active as etherbased compounds. The ester-based compounds (e.g., CSA-44) were prepared from cholic acid, and some of the resulting compounds showed activity that rivaled that of the ether-based compounds. A feature of the ester-based compounds is that the ester groups spontaneously hydrolyzed in water (halflife of 37 days at $\mathrm{pH} 7$ ). Hydrolysis of all of the esters gave cholic acid, an amino acid and a waxy alcohol [47-49].

\subsection{MECHANISM OF ACTION OF CERAGENINS}

A primary mode of antimicrobial activity of AMPs involves selective association with microbial membranes, and this association is mediated by ion pairing of positively charged AMPs with negatively charged microbial membranes [50]. Similarly, ceragenins selectively associate with negatively charged components of bacterial cell membranes, and ceragenins have been shown to sequester bacterial endotoxins (e.g., LPS and lipoteichoic acid), which make up membranes of Gram-negative and positive bacteria [51,52]. This affinity for bacterial membrane components translates into cell selectivity; in studies with intact cells, ceragenins were shown to selectively associate with 
prokaryotes over mammalian cells, and this selective affinity is likely due to the higher net negative charge present on prokaryotic membranes [25].

As a consequence of the interactions of AMPs with the outer membranes of Gram-negative bacteria, blebs form on the surface [53-55], and similar morphological changes occur with ceragenin-treated, Gram-negative bacteria [44]. This observation, along with measurement of affinity of ceragenins for the lipid A portion of lysophosphatidic acid (LPA) and the cell selectivity described above, attest to the interactions between ceragenins and the outer membranes of Gram-negative bacteria. However, perturbation of the outer membrane is insufficient for cell death, and the ultimate target must be the cytoplasmic membrane $[56,57]$. As described above, a lipid chain extending from C24 is required for ceragenins to traverse the outer membrane of Gramnegative bacteria and gain access to the cytoplasmic membrane. A ML-35p mutant strain of $E$. coli was used to show that ceragenins containing such a lipid chain traverse the outer membranes of Gram-negative bacteria and to gain access to the cytoplasmic membrane [36]. Association of ceragenins with the cytoplasmic membranes of bacteria, in sufficient concentrations, leads to formation of transient membrane defects, membrane depolarization and cell death. This mechanism of action is best described by the carpet model proposed for the activity of AMPs with bacteria [25]. Although antiviral and antifungal mechanisms of action of ceragenins are not completely understood, electron micrographs of ceragenin-treated vaccinia virus exhibited considerable morphological changes in the viral lipid envelope, and ceragenintreated fungal cells displayed changes in cell shape, similar to that observed with AMPs [58]. 


\subsection{ANTIMICROBIAL SPECTRUM OF ACTIVITY OF CERAGENINS}

\subsubsection{Antibacterial activity}

The antimicrobial activities of ceragenins have been studied more with bacteria than with other organisms (e.g., fungi and viruses). While they display activity against both Gram-positive and Gram-negative bacteria, ceragenins tend to be active at lower concentrations against Gram-positive bacteria, possibly due to the permeability barrier of the outer membranes of Gramnegative bacteria. Ceragenins have shown activity against a wide array of clinical isolates and drug-resistant bacteria, supporting their potential for clinical use as the threat of antibiotic-resistant bacteria grows [45,59]. To highlight the broad-spectrum antibacterial activities of ceragenins, their abilities to eliminate drug-organisms are highlighted below.

Susceptibility experiments of CSA-13 with four clinical isolates of vancomycinresistant $S$. aureus and 50 clinical isolates of glycopeptide-intermediate and heterogeneous glycopeptide-intermediate $S$. aureus showed that the $\mathrm{MIC}_{50}$, $\mathrm{MIC}_{90}$ and $\mathrm{MBC}$ of all isolates was $1 \mu \mathrm{g} \mathrm{mL}^{-1}$ [60]. These results demonstrate that there is no cross reactivity between glycopeptides and ceragenins. A more pressing concern may be with multi-drug resistant Gram-negative pathogens, and in a study with 60 carbapenem-resistant Acinetobacter baumannii strains isolated from blood specimens of bacteremia patients, CSA-13 gave $\mathrm{MIC}_{50}$ and MIC $_{90}$ of 2 and $8 \mu \mathrm{g} \mathrm{mL}^{-1}$, respectively. Similar results were observed with 50 strains of Pseudomonas aeruginosa isolated from cystic fibrosis patients [61].

Resistance to antibiotics of last resort, such as colistin, is of particular concern [62]. Colistin, AMPs, and ceragenins share common structural features (e.g., multiple cationic amines and hydrophobic character), and this led to the concern that colistin-resistance might also confer resistance to AMPs and ceragenins. A study of selected ceragenins (CSA-13, CSA-44, CSA-131, CSA-138 and CSA-142) and AMPs (LL-37, megainin 1 and cecropin A) revealed that both ceragenins and AMPs are active against highly colistin-resistant Klebsiella pneumoniae isolates. Furthermore only minor differences were observed in the kinetics of the bactericidal activity of ceragenins among the colistin-resistant and colistin-susceptible strains, indicating that colistin-resistance does not remarkably influence the susceptibility of these pathogens to ceragenins [63]. In a separate study, assessment of four ceragenins, CSA-138, CSA-13, CSA-131 and CSA-44, against clinical isolates of colistin-resistant and susceptible P. aeruginosa (MIC 0.5-1 $\mu \mathrm{g} \mathrm{mL}^{-1}$ ) and A. baumannii (MIC 2-8 $\mu \mathrm{g} \mathrm{mL}^{-1}$ ) showed that MICs among susceptible and resistant strains are identical or comparable [63].

Ceragenins have also shown activity against cariogenic and periodontopathic bacteria [37]. Susceptibilities of broad-spectrum pathogens associated with oral and upper respiratory tract infections including Streptococcus mutans (the 
leading etiological agent of dental caries) and S. aureus (which often colonizes the nasopharynx) were determined with ceragenins CSA-13, CSA-90 and CSA92 and compared to LL-37. As shown in Table 1, all tested ceragenins revealed significantly potent antibacterial activity when compared to LL-37 [64]. Interestingly, Lactobacillus casei, considered a beneficial member of the gut microfluora, was much less susceptible to ceragenins and LL-37 than other organisms, indicating a possible adaptation of this strain to become tolerate of LL-37 and probably ceragenins.

Table 1. MIC $[\mathrm{MBC}] \mu \mathrm{g} \mathrm{mL} \mathrm{L}^{-1}$ of LL-37 and ceragenins against tested strains associated with oral infections

\begin{tabular}{ccccc}
\hline Strains & LL-37 & CSA-13 & CSA-90 & CSA-92 \\
\hline $\begin{array}{c}\text { Staphylococcus aureus } \\
\text { ATCC 29213 }\end{array}$ & $14[28]$ & $0.7[1.4]$ & $0.7[2.8]$ & $0.75[0.75]$ \\
\hline $\begin{array}{c}\text { Streptococcus salivarius } \\
\text { ATCC 13419 }\end{array}$ & $14[28]$ & $0.7[1.4]$ & $0.7[1.4]$ & $1.5[3.0]$ \\
\hline $\begin{array}{c}\text { Streptococcus sanguinis } \\
\text { ATCC 10556 }\end{array}$ & $14[28]$ & $0.7[0.7]$ & $1.6[1.4]$ & $1.5[3.0]$ \\
\hline $\begin{array}{c}\text { Streptococcus mutants } \\
\text { ATCC 35668 }\end{array}$ & $28[28]$ & $0.7[1.4]$ & $0.7[1.4]$ & $0.75[1.5]$ \\
\hline $\begin{array}{c}\text { Enterococcus faecalis } \\
\text { ATCC 29212 }\end{array}$ & $28[56]$ & $2.8[2.8]$ & $1.4[2.8]$ & $8.0[3.0]$ \\
\hline $\begin{array}{c}\text { Moraxella catarrhalis } \\
\text { ATCC 23246 }\end{array}$ & $28[28]$ & $1.4[1.4]$ & $0.7[1.4]$ & $0.35[1.5]$ \\
\hline $\begin{array}{c}\text { Peptostreptococcus } \\
\text { Anaerobius ATCC 27337 }\end{array}$ & $224[224]$ & $5.6[5.6]$ & $22.4[22.4]$ & $5.8[11.7]$ \\
\hline $\begin{array}{c}\text { Lactobacillus casei } \\
\text { ATCC 393 }\end{array}$ & $224[224]$ & $22.4[44.8]$ & $44.8[44.8]$ & $46.8[46.8]$ \\
\hline $\begin{array}{c}\text { Fusobacterium nucleatum } \\
\text { ATCC 25586 }\end{array}$ & $224[224]$ & $11.2[22.4]$ & $11.2[11.2]$ & $11.7[23.4]$ \\
\hline & & & & \\
\hline
\end{tabular}

The permeability barrier of the outer membranes of Gram-negative bacteria and the action of efflux pumps in these membranes contribute to resistance profiles of bacteria [65]. Association of ceragenins with the outer membranes decreases the permeability barrier resulting in synergy between ceragenins and other antibiotics [66]. For example, synergistic activities of CSA-13 were reported with colistin, tobramycin, and ciprofloxacin against P. aeruginosa strains isolated from cystic fibrosis patients. The synergistic effect of CSA-13 was stronger with colistin (54\% of tested strains) compared to tobramycin (25\% of tested strains) [67]. Further investigation showed that CSA-13 also displays synergistic activity with cefepime or ciprofloxacin against clinical 
isolates of $P$. aeruginosa, including multidrug-resistant $P$. aeruginosa [68]. In related studies, the synergistic effects of ceragenins with AMPs were studied; combinations of CSA-13 with selected AMPs LL-37, lysozyme, lactoferin, or secretory phospholipase A were evaluated against bacteria causing topical infections. As expected, CSA-13 exhibited more potent antibacterial activity in the presence of all tested AMPs [69].

\subsubsection{Antifungal activity}

The continued emergence of drug-resistant fungal pathogens has highlighted the urgent need for novel antifungal agents [70]. AMPs display antifungal activity [13] and this observation led to the question of whether ceragenins, as mimics of AMPs, would also display antifungal activity. Fungicidal activity of ceragenins CSA-13, CSA-131 and CSA-192 was evaluated against four fluconazole-resistant Candida strains [71]. Interestingly, these ceragenins showed higher antifungal activity against these strains than LL-37 and omiganan, a synthetic AMP designed for antifungal activity. In addition to Candida spp., CSA131 and CSA-192 were also found to be active against a broad array of fungal strains including Cryptococcus, Aspergillus, Scedosporium, Rhizopus and Blastomyces.

Recently, the global emergence of invasive infections caused by drug-resistant Candida auris has become a serious threat to public health. A high percentage of clinical isolates of $C$. auris are resistant to fluconazole and at least one of the other major classes of antifungals (polyenes and echinocandins) [72,73]. Already shown to be active against Candida albicans, lead ceragenins were selected for testing against $C$. auris [74]. The Center for Disease Control and Prevention determined the susceptibility of 100 clinical isolates of $C$. auris to CSA-131. They found that the $\mathrm{MIC}_{50}$ and the $\mathrm{MIC}_{90}$ were $1 \mu \mathrm{g} \mathrm{mL}^{-1}$, and no loss of activity of CSA-131 was found among fluconazole-resistant or echinocandinresistant isolates. Further studies with a smaller collection of $C$. auris isolates were performed with ceragenins CSA-13, CSA-44, CSA-131, and CSA-144, along with caspofungin, amphotericin $B$ and fluconazole, representatives of the three major classes of antifungal agents in clinical use. The selected ceragenins showed MICs comparable to those of caspofungin and amphotericin B; however, as expected fluconazole was weakly active against the $C$. auris strains (Table 2). Notably, minimum fungicidal concentrations (MFCs) of the ceragenins were significantly lower than those of caspofungin and amphotericin B with most of the clinical isolates. 
Table 2. MIC [MFC] $\mu \mathrm{g} \mathrm{mL} \mathrm{m}^{-1}$ of ten clinical isolates of $C$. auris to selected ceragenins and three major classes of antifungal agents

\begin{tabular}{|c|c|c|c|c|c|c|c|}
\hline Strains & CSA-44 & CSA-131 & CSA-142 & CSA-144 & CPF & AMB & FLZ \\
\hline C. auris & 0.5 & 0.5 & 4.0 & 0.5 & 2.0 & 1.0 & 16 \\
\hline CDC381 & [2.0] & [8.0] & [32] & [2.0] & [64] & [48] & {$[>100]$} \\
\hline C. auris & 0.5 & 0.5 & 4.0 & 1.0 & $\mathrm{~nm}$ & $\mathrm{~nm}$ & $\mathrm{~nm}$ \\
\hline CDC382 & [4.0] & [8.0] & [24] & [8.0] & & & \\
\hline C. auris & 0.5 & 1.0 & 2.0 & 1.0 & 32 & 1.0 & 64 \\
\hline CDC 383 & [8.0] & [10] & [64] & [8] & [64] & [32] & {$[>100]$} \\
\hline C. auris & 0.5 & 0.5 & 4.0 & 1.0 & $\mathrm{~nm}$ & $\mathrm{~nm}$ & $\mathrm{~nm}$ \\
\hline CDC384 & [4.0] & [4.0] & [24] & [8.0] & & & \\
\hline C. auris & 0.5 & 0.5 & 8.0 & 1.0 & $\mathrm{~nm}$ & $\mathrm{~nm}$ & $\mathrm{~nm}$ \\
\hline CDC385 & [16] & [4.0] & [32] & [8.0] & & & \\
\hline C. auris & 0.5 & 1.0 & 4.0 & 0.5 & 2.0 & 2.0 & 64 \\
\hline CDC386 & [8.0] & [8.0] & [32] & [8.0] & [64] & [48] & {$[>100]$} \\
\hline C. auris & 0.5 & 0.5 & 4.0 & 0.5 & $\mathrm{~nm}$ & $\mathrm{~nm}$ & $\mathrm{~nm}$ \\
\hline CDC387 & [8.0] & [8.0] & [32] & [8] & & & \\
\hline C. auris & 1.0 & 0.5 & 4.0 & 2.0 & $\mathrm{~nm}$ & $\mathrm{~nm}$ & $\mathrm{~nm}$ \\
\hline CDC388 & [8.0] & [4.0] & [24] & [8.0] & & & \\
\hline C. auris & 0.5 & 0.5 & 4.0 & 1.0 & $\mathrm{~nm}$ & $\mathrm{~nm}$ & $\mathrm{~nm}$ \\
\hline CDC389 & [8.0] & [8.0] & [24] & [8.0] & & & \\
\hline C. auris & 0.5 & 0.5 & 4.0 & 1.0 & 2.0 & 4.0 & 64 \\
\hline CDC390 & [8.0] & [4.0] & [16] & [8.0] & [100] & [64] & {$[>100]$} \\
\hline C. albicans & 0.5 & 0.5 & 2.0 & 2.0 & 2.0 & 2.0 & 24 \\
\hline $\begin{array}{l}\text { ATCC } \\
90028\end{array}$ & [8.0] & [4.0] & [8.0] & [8.0] & [32] & [100] & {$[>100]$} \\
\hline
\end{tabular}

CPF: caspofungin, AMB: amphotericin B, FLZ: fluconazole. nm: not measured

The primary antifungal mechanism of action of AMPs is proposed to involve interactions and potentially disruption of the fungal membrane. Apoptosis as a result of increased reactive oxygen species (ROS) and decreased mitochondrial function have been also observed [75-78]. Although the antifungal mechanism of ceragenins is not still completely understood, atomic force and scanning electron microscopy of candida cells treated with ceragenins shows significant changes in the surface cell morphology compared to untreated cells (Figure 2), suggesting they act via interactions with fungal membranes and similarly to AMPs. In a recent study, LL-37 or CSA-13 immobilized on magnetic nanoparticles were to shown to increase ROS generation in fungal cells, suggesting an additional pathway of antifungal activity with Candida spp. (Figure 3) [79]. Nevertheless, additional information is still required to fully understand how ceragenins target and kill fungal cells. 

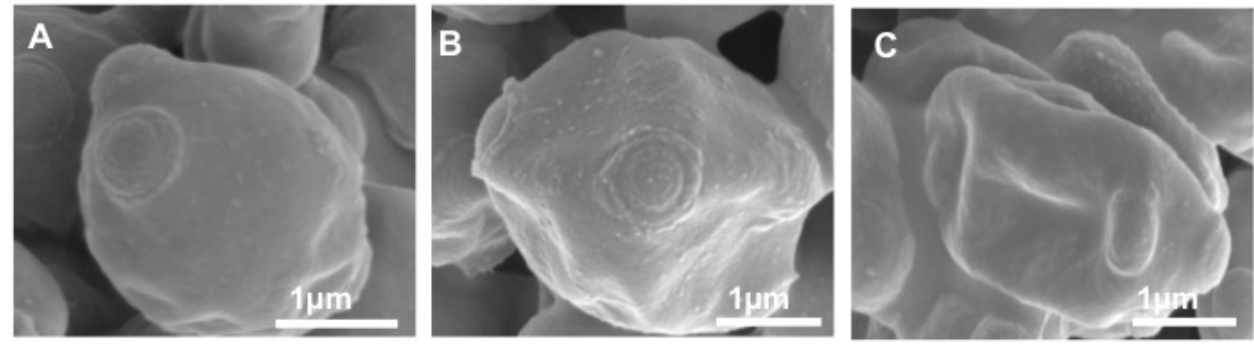

Figure 2. Scanning electron microscope (SEM) images of untreated C. auris CDC390 (A), treated with CSA-131 $25 \mathrm{mg} \mathrm{L}^{-1}$ (B) and $50 \mathrm{mg} \mathrm{L}^{-1}$ (C)

Positively charged
MNP@LL-37/CSA-13

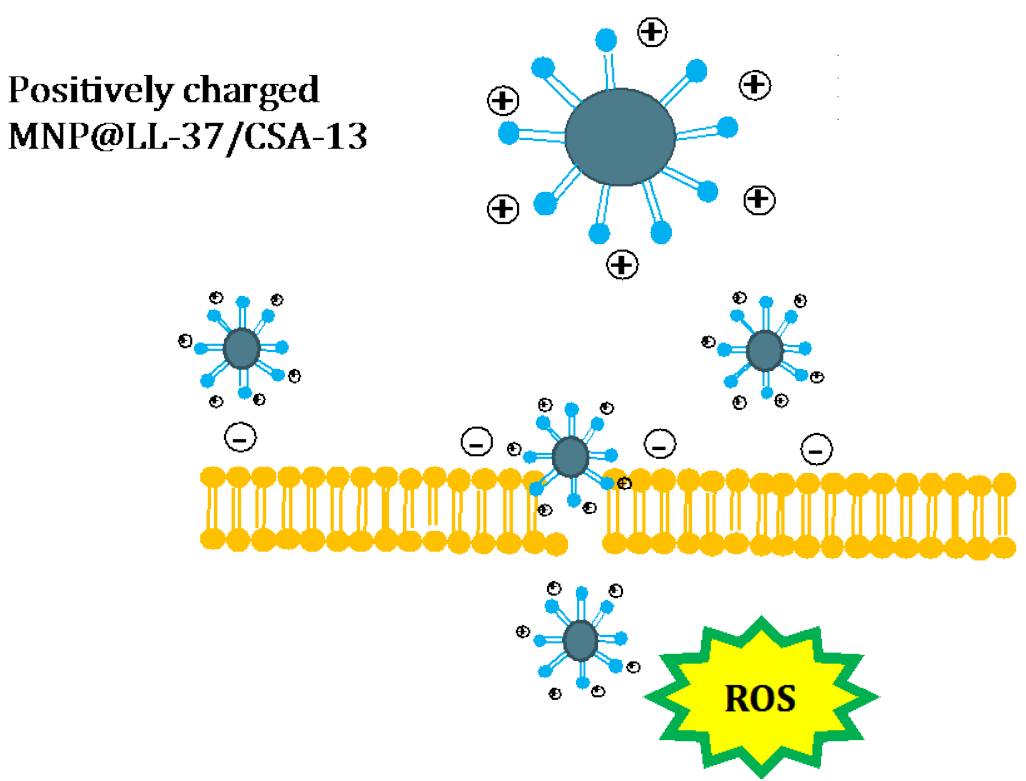

1. Interaction of MNP@LL-37/ CSA-13 to the cell membrane

2. Disruption of cell membrane

3. Internalization of MNP@LL-37/ CSA-13 and ROS generation

4. Cell death

Figure 3. Proposed mechanism of positively charged coated magnetic nanoparticles with LL-37 or CSA-13 against fungal cells membrane and contribution of LL-37/CSA-13 to generation of ROS 


\subsubsection{Antibiofilm activity}

Bacteria and fungi naturally exist in planktonic and biofilm forms. Planktonic cells are single, free-growing microorganisms, while biofilms form from groups of cells that aggregate through a protective extracellular polymeric matrix [80]. Biofilms are now thought to be involved in most infections, including chronic wounds, medical device-related infections, and cystic fibrosis-associated pneumonia. Eradication of biofilms can be a particularly daunting task due to the protective environment provided by the extracellular matrix and because cells within the biofilm are slow-growing and have low metabolic activity and therefore do not respond to antibiotics that target and inhibit cells that are rapidly growing and reproducing [81]. These factors lead to a 100-1,000-fold increase in the ability of the bacteria or fungi to resist antibiotic treatment, compared to planktonic cells [13]. For example, $\beta$-lactam antibiotics inhibit the synthesis of the peptidoglycan layer of the bacterial cell wall and while their effect is considered bactericidal, it is most effective against cells that are growing and preparing to divide, as they require more peptidoglycan [82]. Consequently, $\beta$-lactams lose activity as bacteria transition from planktonic to sessile forms found in biofilms. Ceragenins and AMPs, on the other hand, target the bacterial membrane, and are able to kill bacterial and fungal cells regardless of whether they are rapidly growing, dividing, or sessile [83]. In addition, the relatively small size of ceragenins allows them to penetrate the extracellular matrix of biofilms and gain access to the cells within [38]. A comparative study of ceragenins with ciprofloxacin indicated that a much lower concentration of CSA-13 was required to eradicate an established biofilm consisting of a meticillin-resistant strain of $S$. aureus in comparison with ciprofloxacin. While treatment with CSA-13 caused a complete eradication of biofilm at a concentration between 16 and $32 \mu \mathrm{g} \mathrm{mL} \mathrm{L}^{-1}$, treatment with ciprofloxacin resulted in an insignificant reduction of biofilm even at a concentration of $64 \mu \mathrm{g} \mathrm{mL}^{-1}$ [84]. In a similar study, it was observed that CSA13 inhibits biofilm formation of both mucoid and nonmucoid phenotypes of $P$. aeruginosa at $1 \mu \mathrm{g} \mathrm{mL}^{-1}$ [85]. It was also noted that the rhlAB operon, which is controlled by quorum sensing and regulates rhamnolipid synthesis, was not an intracellular target of CSA-13 involved in the inhibition of biofilm formation. Further study with confocal laser scanning images of biofilms formed by $P$. aeruginosa revealed that bactericidal penetration of ceragenins into the biofilm matrix occurs within only 30 minutes of exposure of the ceragenin to the established biofilm [86].

In a recent study, the ability of clinical isolates of $C$. auris and $C$. albicans to form biofilms was quantified by measuring metabolic activity through use of XTT reagent in a colorimetric assay [74]. Under identical conditions, C. auris showed less metabolic activity than $C$. albicans, indicating a lower ability of $C$. auris to form biofilm compared to $C$. albicans. The concentrations of ceragenins necessary to reduce biofilms by 50 and $80 \%$ were then determined. Ceragenins revealed similar or superior antibiofilm activity against sessile 
organisms in established biofilms when compared to amphotericin B, caspofungin, and fluconazole.

\subsubsection{Sporicidal activity}

Some genera of bacteria such as Bacillus and Clostridium undergo a process of sporulation in response to unfavorable environmental conditions including depletion of nutrients [87]. Sporulation enables bacteria to form inert, dormant spores, and this process involves formation of a multilayered structure different than vegetative cells [88]. Given the membranepermeabilizing properties of ceragenins, activity of CSA-13 against the vegetative and spore forms of $B$. subtilis was assessed [89]. Treatment with CSA-13 significantly diminished the viability of vegetative cells and inhibited spore germination. Moreover, the surface electrical features of spores and vegetative cells measured through zeta potential provided evidence that the surfaces of spores exhibit a larger negative charge than vegetative cells. It was postulated that this charge density was the cause of the high affinity of CSA-13 spore surfaces. Raman spectroscopy analysis further illustrated that ceragenin-treated spores release more calcium dipicolinic acid than untreated cells, implying that there is an increased permeability in the barriers of these spores, which increases their susceptibility to ceragenins.

\subsubsection{Antiviral activity}

AMPs exhibit antiviral activity through several mechanisms. First, by targeting the viral envelopes of lipid-enveloped viruses and disrupting membrane integrity, AMPs cause viruses to lose the ability to infect the host cells. Second, AMPs block viral receptors on the cell surface and prevent viruses from binding to host cells [13]. This can be seen in the interaction between $\theta$ defensins and viral glycoproteins of the Herpes simplex virus [90]. The antiviral activity of LL-37 against vaccinia virus has been established, and subsequently the antiviral activity of CSA-13 was studied against the same virus, which is a large double-stranded DNA virus that can infect a wide variety of mammalian cells as well as invertebrate cells [58]. CSA-13 showed potent antiviral activity through targeting the viral envelope. Additionally, topical application of CSA-13 in a murine model of vaccinia infection showed a substantial reduction in the number of satellite lesions that formed and in viral replication in the epidermis of infected mice.

\subsubsection{Anti-parasite activity}

The actions of a few AMPs have been studied with parasites, and anti-parasitic activities have been attributed to direct interactions with cell membranes. Magainins were reported as the first AMPs with anti-parasitic properties, displaying activity against Paramecium caudatum [14]. Cathelicidin is another example of an anti-parasite AMP, with activity against Caernohabditis elegans 
through pore formation on the cell membrane [91]. CSA-13 was also tested for anti-parasitic activity and showed an $\mathrm{LD}_{50}$ of $c a .9$ and $5 \mu \mathrm{M}$ with Trypanosoma cruzi and Leishmania major, respectively [92]. Acanthamoeba castellanii is a causative agent of corneal infections known as acanthamoeba keratitis. The parasite has two phases of life cycle, including cysts (the most resistant form) and trophozoites (the replicating stage) [93]. An in vitro evaluation of CSA-13 at concentrations of $25,50,75$, and $100 \mathrm{mg} \mathrm{mL}^{-1}$ against both cyst and trophozoite forms of $A$. castellanii showed that CSA-13 inhibited trophozoite growth in a dose- and time-dependent manner. For example, within one hour of exposure to $100 \mathrm{mg} \mathrm{mL}^{-1} \mathrm{CSA}-13$, no viable trophozoites were detected [94]. Further study was performed using ceragenins CSA-13, CSA-44, CSA-131, and CSA-138 against metronidazole-susceptible and metronidazole-resistant strains of Trichomonas vaginalis, a parasitic protozoan transmitted via sexual intercourse and hosted only in humans. Overall, all tested ceragenins killed the tested T. vaginalis with a similar activity against metronidazole-susceptible and resistant strains, and CSA-13 was the most effective ceragenin in this study [95].

\subsection{MICROBIAL RESISTANCE TO AMPS AND CERAGENINS}

AMPs have existed for eons and have played a central role in nearly all organisms in controlling the growth of pathogens. Even most common pathogens have been exposed to AMPs for extended periods, most remain susceptible to AMPs, while pathogens have developed high levels of resistance to most other clinically-used antibiotics [96]. The cause of the enduring activity of AMPs may be due to a variety of factors: First, AMPs have co-evolved with the pathogens they are fighting, and through natural selection AMPs with optimized properties are selected for as they increase the fitness of their host. Second, while some AMPs are constitutively expressed, some are only released or have their expression substantially up-regulated with infection or inflammation. This non-constitutive and localized expression may also hinder a pathogen's ability to form resistance as it never is allowed to adapt to an environment that contains sub-therapeutic levels of AMP [97]. Finally, AMPs target the membranes of microorganisms rather than specific enzymatic pathways. Consequently, resistance to AMPs requires modification to a gross structural component of microorganisms, a process that may come with a metabolic cost or substantial changes in interactions of the microorganisms with their environment [98]. However, bacteria are not totally defenseless against AMPs [13]. Some bacterial pathogens, for example $S$. mutans, produce and release metalo-proteases, and it has been hypothesized that these are designed to destroy AMPs. Prolonged exposure of Gram-negative bacteria to AMPs results in modifications to the lipid A portion of LPS. For example, in 
Salmonella typhimurium this modification is caused by two-component signal transduction systems including PhoP-PhoQ and PmrA-PmrB [99]. The presence of positive charges on AMPs activates PhoQ, which is a membraneassociated protein kinase, and activated PhoQ phosphorylates PhoP, which leads to upregulation of a host of proteins including PagP leading to the addition of palmitate to membrane-associated lipid A. This change increases the hydrophobic character of lipid A and membrane stiffness. The same signal transduction system also leads to further modification of lipid A through formation of phosphate esters with ethanolamine and L-4-amino arabinose [100-102]. These changes decrease the net negative charge of the membrane and further decreases the affinity of AMPs to the bacterial membrane. These defenses, however, are metabolically costly to bacteria, and absent AMPs or other threats, bacteria shut down these systems and exist in AMP-susceptible forms. It is also interesting to note that although resistance to AMPs has been observed in vitro, no evidence of resistance in vivo has been observed to this point [30].

To investigate the potential for bacteria to generate resistance to ceragenins, selected Gram-negative and Gram-positive bacteria were serially passaged with varied concentrations of lead ceragenins CSA-13 and CSA-131 [63,103]. Comparator antibiotics were ciprofloxacin and vancomycin with Gram-positive bacteria and ciprofloxacin and colistin with Gram-negative bacteria. With both Gram-positive and -negative bacteria, MICs with ciprofloxacin increased to high levels $\left(>50 \mu \mathrm{g} \mathrm{mL}^{-1}\right)$ with relatively few passages of $24 \mathrm{~h}$. The MIC of vancomycin increased ca. 10 -fold with $S$. aureus over 30 passages of $24 \mathrm{~h}$, while only a small change of MIC (less than two-fold) occurred over the same number of passages with CSA-13 [103]. With Gram-negative bacteria, the MIC of colistin increased to $>100 \mu \mathrm{g} \mathrm{mL}^{-1}$ within 20 passages of $24 \mathrm{~h}$, and over 30 passages of $24 \mathrm{~h}$, the MIC of CSA-13 increased to $20-30 \mu \mathrm{g} \mathrm{mL}^{-1}$. In contrast, the MIC of CSA-131 from 1-2 $\mu \mathrm{g} \mathrm{mL}^{-1}$ to $2-8 \mu \mathrm{g} \mathrm{mL}-1$ over 30 passages of $24 \mathrm{~h}$ with P. aeruginosa, and A. baumanni and Klebsiella pneumoniae (Figure 4) [63]. 

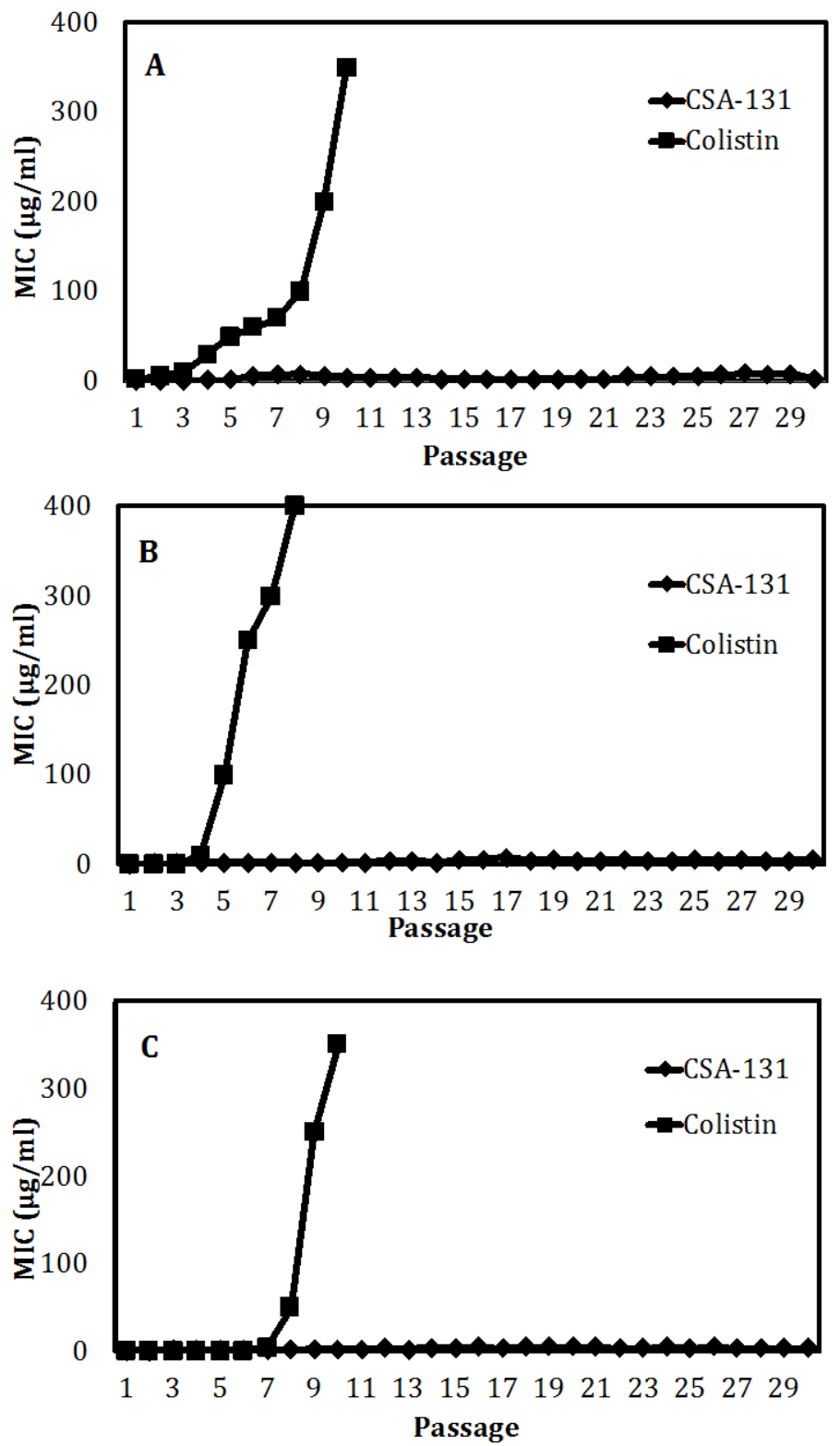

Figure 4. The MICs of colistin and CSA-131 against K. pneumoniae (A), A. baumannii (B) and P. aeruginosa (C) after the number of days ( $24 \mathrm{~h}$ periods) of exposure

To understand Gram-negative bacterial responses to serial passaging with colistin or CSA-131, lipid A was isolated from the membranes of seriallypassaged strains and analyzed via mass spectroscopy [63]. As is the case with AMP-resistance, modification of lipid A through the addition of 4- 
aminorabinose, ethanolamine, and fatty acids was observed with strains exposed to either colistin or CSA-131, likely as a result of the activation of twocomponent systems such as PhoP/PhoQ and PmrA/PmrB. However, as seen previously, the highly colistin resistant strain was fully susceptible to CSA-131, suggesting that mechanisms other than lipid A modification are likely involved in colistin resistance. These results offer evidence that the ceragenins are less likely to engender resistance than other antibiotics.

The antimicrobial activities of AMPs and ceragenins may be influenced not only by modifications made by bacteria but also by production of specific molecules produced by the host. Because mucins, DNA and F-actin have been shown to deactivate AMPs, the question arose of how these compounds would impact the activities of ceragenins. Comparative studies showed that these molecules had much less impact on the antibacterial activities of ceragenin CSA-13 than AMPs [52,104]. This observation is particularly important for potential applications of ceragenins in treating infections associated with cystic fibrosis. Mucins, DNA and F-actin are produced at relatively high concentrations in the lungs of those with cystic fibrosis. The smaller size of CSA-13 and lower positive charge, relative to endogenous AMPs, were proposed to be why the antibacterial activity of CSA-13 is less compromised by mucins, DNA and F-actin than AMPs. In a following study, the effects of selected depolymerizing factors (plasma gelsolin, DNase 1, and poly-asparate) on polyelectrolyte networks of F-actin and DNA in purulent body fluids were assessed in order to determine if they would improve the bactericidal activities of CSA-13, LL-37, tobramycin, colistin and polymyxin [105]. The depolymerizing compounds were found to enhance the activities of the tested antimicrobials, particularly CSA-13 and LL-37. Stronger antibacterial activity was observed with combination of DNase 1 and poly-aspartate as compared to the individual depolymerizing compounds [105]. These results provide strong evidence that because ceragenins possess potent antibacterial activity that is even sustained in the presence of complex anionic compounds, they offer excellent potential in treating chronic lung infections in cystic fibrosis patients, where the accumulation of polyanions creates major treatment obstacles. 


\subsection{EFFECT OF POLOXAMER MICELLES ON THE ANTIMICROBIAL ACTIVITIES AND CYTOTOXICITY OF CERAGENINS}

Clinical use of AMPs and ceragenins requires selective toxicity for microorganisms over host cells. One measure of cytotoxicity used to evaluate membrane-active compounds is measurement of concentrations of investigational antimicrobials that cause hemolytic activity. One such study showed that CSA-13 is not hemolytic at concentrations required for bactericidal activity and hemolysis was first observed at concentrations 10 times the bactericidal concentration [52]. Further evaluation of hemoglobin release from human red blood cells showed that CSA-13 at a concentration of $10 \mathrm{mg} \mathrm{mL}^{-1}$ causes lysis in less than $10 \%$ of erythrocytes while total hemolysis occurs at a concentration of $50 \mathrm{mg} \mathrm{mL}^{-1}$ [106]. These concentrations are higher than the concentrations required for bactericidal activity of ceragenins. In studies with HaCat cells, the toxicity profile of CSA-13 was similar to that of LL-37, without any toxicity at bactericidal concentrations [64].

Cytotoxicity was explored in a comparative study of ceragenins with bacterial cells and human umbilical vein endothelial cells. It was found that CSA-13 permeabilizes the plasma membrane of these eukaryotic cells in addition to the bacteria cells [107]. In an attempt to attenuate this effect of CSA-13 on eukaryotic cells, it was combined with the poloxamer Pluronic $\AA$ F-127, a nonionic surfactant comprised of polyoxyethylene-polyoxypropylene copolymers (hereafter referred to as pluronic). The low toxicity of this poloxamer, great solubilizing capacity, and unique thermoreversible and drug releasing properties contribute to its applications in drug delivery as a pharmaceutical vehicle [108]. This poloxamer forms micelles that associate with hydrophobic and amphiphilic compounds. Formulation of ceragenins with pluronic resulted in well-defined micelles with lower toxicity toward eukaryotic cells, while antibacterial activity was not substantially impaired $[69,109]$. Studies included co-formulation of ceragenins and pluronic and showed that association of ceragenins in poloxamer micelles allowed them to maintain their antibacterial and antifungal activities against planktonic organisms as well as established biofilms.

An additional means of determining possible cytotoxicity of ceragenins involves use of ciliated explants from the trachea or lung. Epithelial cells in these tissues produce cilia, which beat to move particles from the trachea and lung to the throat. Thus cilia beating can act as a surrogate for measurement of even minor insults to epithelial cells [110-112]. Using tissue explants, high concentrations of ceragenin CSA-131 were shown to negatively impact cilia beating. However, formulation of CSA-131 with pluronic resulted in complete retention of cilia beating, indicating that the underlying epithelial cells were unaffected even by relatively high concentrations of CSA-131 (100 $\left.\mu \mathrm{g} \mathrm{mL}^{-1}\right)$. Furthermore, SEM images (Figure 5) of ciliated trachea showed that CSA-131 
formulated with pluronic left cilia intact, while CSA-131 at $100 \mu \mathrm{g} \mathrm{m}^{-1}$ resulted in loss of cilia. The antifungal activity of CSA-131 was entirely sustained in the infected trachea and lung. Therefore, CSA-131 formulated in micelles may act as an appropriate candidate for the treatment of polymicrobial and biofilm-related infections in lung and trachea [113].
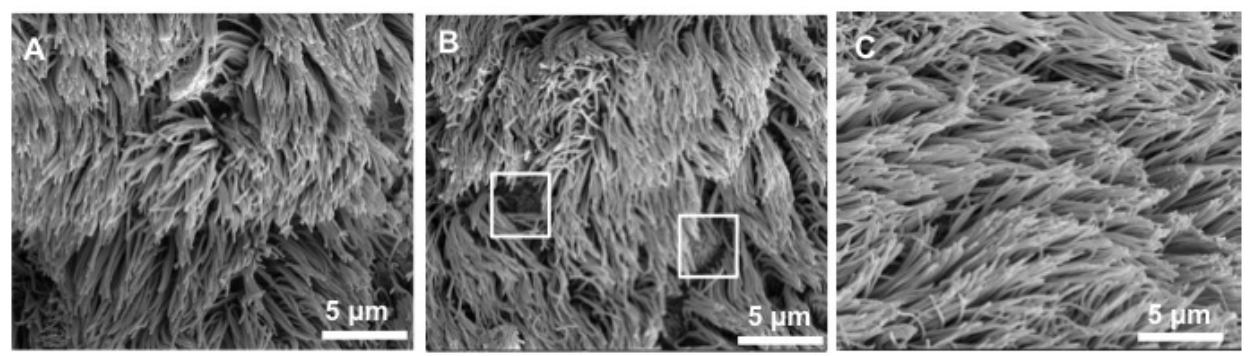

Figure 5. SEM images of ciliated surface of a porcine trachea explants. Untreated (A), treated with CSA-131 at $100 \mu \mathrm{g} \mathrm{mL}^{-1}$ (B), treated with CSA-131 at $100 \mu \mathrm{g} \mathrm{mL}^{-1}$ with $4 \%$ pluronic (C). Exposed goblet cells are shown with white squares in the image from treatment with CSA-131 without pluronic.

\subsection{NANOPARTICLES AS CARRIERS OF CERAGENINS}

Metal-based nanoparticles provide a unique platform for the presentation of ceragenins in a pre-aggregated form. In addition, the distribution of magnetic nanoparticles can be controlled in tissues and silver-based nanoparticles display inherent antimicrobial activity. Multiple methods have proven effective in attaching ceragenins to nanoparticles. One method uses CSA-124, a ceragenin formulated with a thiol group appendage. The thiol group can coordinate with thiophilic metals, such as silver, producing a monolayer on the surface of the nanoparticles [114]. Another method requires the generation of an aldehyde-containing surface on the nanoparticles. Ceragenins contain multiple amine groups, and these groups reversibly form Schiff bases with the aldehydes. On a surface with high aldehyde density, nanoparticles can then aggregate ceragenins in high concentrations [115].

Hoppens et al. [114] coated silver nanoparticles with CSA-124 and found that they were five times more bactericidal than silver alone. These nanoparticles displayed MICs of $c a .12$ and $24 \mathrm{ppm}$ against $S$. aureus and E. coli, respectively. Niemirowicz etal. [115] showed that magnetic nanoparticles coated with ceragenins retained their bactericidal activity. This association also increased the biocompatibility of ceragenins. Further testing also showed that even 
without direct conjugation of ceragenin to the nanoparticle, synergistic activity between nanoparticles and ceragenins occurred [116].

Durnás et al. [117] also evaluated magnetic nanoparticles for their activity against selected anaerobic bacteria often implicated in human disease. In vitro models testing CSA-13 and CSA-131 attached to nanoparticles showed comparable or stronger bactericidal activity against all of the tested strains, which included Bacteroides fragilis, Propionibacterium acnes, and a clinical isolate of Clostridium difficile (Table 3). Nanoprticles including CSA-131 also showed enhanced ability in preventing biofilm formation of Bacteroides fragilis and Propionibacterium acnes. Neimirowicz etal. [79] further studied the candidacidal activity of magnetic nanoparticles coated with CSA-13 and CSA131. Their experiments confirmed that ceragenins attached to nanoparticles retained their highly potent fungicidal activity against multiple laboratory and clinical species of $C$. albicans, C. glabrata, and C. tropicalis.

Table 3. MIC [MBC] $\mu \mathrm{g} \mathrm{mL} \mathrm{m}^{-1}$ of LL-37, CSA-13 and CSA-131 functionalized on nanoparticles against tested anaerobic strains

\begin{tabular}{cccccccc}
\hline Strains & LL-37 & $\begin{array}{c}\text { MNP } \\
\text { @ LL- }\end{array}$ & $\begin{array}{c}\text { CSA- } \\
\mathbf{1 3}\end{array}$ & $\begin{array}{c}\text { MNP@ } \\
\text { CSA-13 }\end{array}$ & $\begin{array}{c}\text { CSA- } \\
\mathbf{1 3 1}\end{array}$ & $\begin{array}{c}\text { MNP@ } \\
\text { CSA- }\end{array}$ & MNP \\
$\mathbf{3 7}$ & & & & & $\mathbf{1 3 1}$ & \\
\hline Bacteroides & 128 & 128 & 4.0 & 2.0 & 8.0 & 4.0 & $>256$ \\
fragilis & {$[256]$} & {$[256]$} & {$[8.0]$} & {$[4.0]$} & {$[16]$} & {$[4.0]$} & {$[>256]$} \\
\hline Bacteroides & 128 & 128 & 8.0 & 2.0 & 8.0 & 16 & $>256$ \\
thetaiotaomicron & {$[128]$} & {$[128]$} & {$[8.0]$} & {$[2.0]$} & {$[8.0]$} & {$[16]$} & {$[>256]$} \\
\hline Bacteroides & 128 & 128 & 2.0 & 2.0 & 8.0 & 16 & $>256$ \\
stercoris & {$[128]$} & {$[256]$} & {$[2.0]$} & {$[2.0]$} & {$[16]$} & {$[32]$} & {$[>256]$} \\
\hline Prevotella & 128 & 128 & 8.0 & 2.0 & 8.0 & 16 & 256 \\
melaninogenica & {$[128]$} & {$[128]$} & {$[8.0]$} & {$[2.0]$} & {$[8.0]$} & {$[16]$} & {$[256]$} \\
\hline Prevotella & 8.0 & 16 & 0.5 & 1.0 & 4.0 & 16 & 256 \\
oralis & {$[8.0]$} & {$[32]$} & {$[0.5]$} & {$[1.0]$} & {$[4.0]$} & {$[16]$} & {$[256]$} \\
\hline Prevotella & 64 & 32 & 1.0 & 2.0 & 2.0 & 2.0 & $>256$ \\
bivia & {$[64]$} & {$[32]$} & {$[1.0]$} & {$[2.0]$} & {$[4.0]$} & {$[4.0]$} & {$[>256]$} \\
\hline Prevotella & 16 & 16 & 1.0 & 1.0 & 2.0 & 4.0 & $>256$ \\
disiens & {$[16]$} & {$[16]$} & {$[1.0]$} & {$[1.0]$} & {$[2.0]$} & {$[4.0]$} & {$[>256]$} \\
\hline Clostridium & 128 & 64 & 1.0 & 1.0 & 4.0 & 16 & $>256$ \\
Perfringens & {$[256]$} & {$[128]$} & {$[1.0]$} & {$[1.0]$} & {$[4.0]$} & {$[16]$} & {$[>256]$} \\
\hline Peptostre- & 8.0 & 16 & 0.5 & 0.5 & 4.0 & 8.0 & $>256$ \\
ptococcus spp. & {$[8.0]$} & {$[16]$} & {$[0.5]$} & {$[0.5]$} & {$[4.0]$} & {$[8.0]$} & {$[>256]$} \\
\hline
\end{tabular}




\subsection{MEDICAL APPLICATIONS OF CERAGENINS}

\subsubsection{Contact lenses}

Contact lenses are abiotic surfaces on which pathogens can form biofilms and proliferate, potentially leading to microbial keratitis, a serious condition that affects up to 25,000 Americans each year. AMPs are present in conjunctival fluid and provide the surface of the eye an innate immune function that controls bacterial growth. Efforts have been made to provide contact lenses with a comparable innate immune function by attaching AMPs to lenses, and this combination reduced the ability of bacteria to colonize lenses [118]. However, the relatively high cost of AMPs and concerns over thermal stability (lenses are generally autoclaved in the final stages of production) complicate the use of AMPs in contact lenses. The relatively low cost of ceragenins and the thermal stability of the ether-based compounds make them attractive alternatives to AMPs in providing an innate immune defense to contact lenses. In addition, ceragenins contain no chromophores (colorless), they are soluble in the polymers used to make lenses and they do not interfere with the polymerization processes involved in lens formation [119].

Two approaches were used in combining ceragenins and contact lenses. The first required appending a ceragenin with an acrylamide group, generating CSA-120 and allowing the ceragenin to participate in the radical polymerization steps that form lenses. The second involved formation of lenses in the presence of ceragenins, and in this approach ceragenins were able to elute from lenses.

Photo-initiated polymerization of acrylate groups is used to form hydrogel contact lenses. Acrylamide groups can participate in the polymerization process, and addition of CSA-120 to the reaction allowed covalent attachment of the ceragenin to the lens hydrogel. Up to $1.25 \%$ CSA-120, relative to the dry mass of a lens, could be incorporated without causing phase separation in the hydrogel. When incorporated at this concentration in lenses, biofilm formation (S. aureus) was reduced by 3 logs after $24 \mathrm{~h}$ when tested in a $10 \%$ bacterial growth medium. When $100 \%$ medium was used, however, this inhibitory effect was lost, likely because the permanently bound ceragenin was covered by bacteria and bacterial debris.

To improve the duration of activity of ceragenins in contact lenses, a series of ceragenins were prepared in which the lengths of the lipid chain extending from bile acid were incrementally varied. The intent of these experiments was to match the hydrophobicity of the ceragenin to the hydrophobic domains in the lens hydrogel to limit elution of the ceragenin from the lens. With a shorter lipid chain, the ceragenin eluted too rapidly; however, with CSA-138, elution extended over weeks and provided antibacterial activity. At $1 \%$ of the weight of dry lenses, CSA-138 inhibited the colonization of lenses by $S$. aureus for up to 30 days and by P. aeruginosa for up to 15 days (Figure 6) with daily inoculation 
with bacteria in fresh media. These results demonstrate that by tuning the properties of ceragenins to a hydrogel, the elution profile of the ceragenin can be controlled to provide long-lasting antimicrobial activity [119].
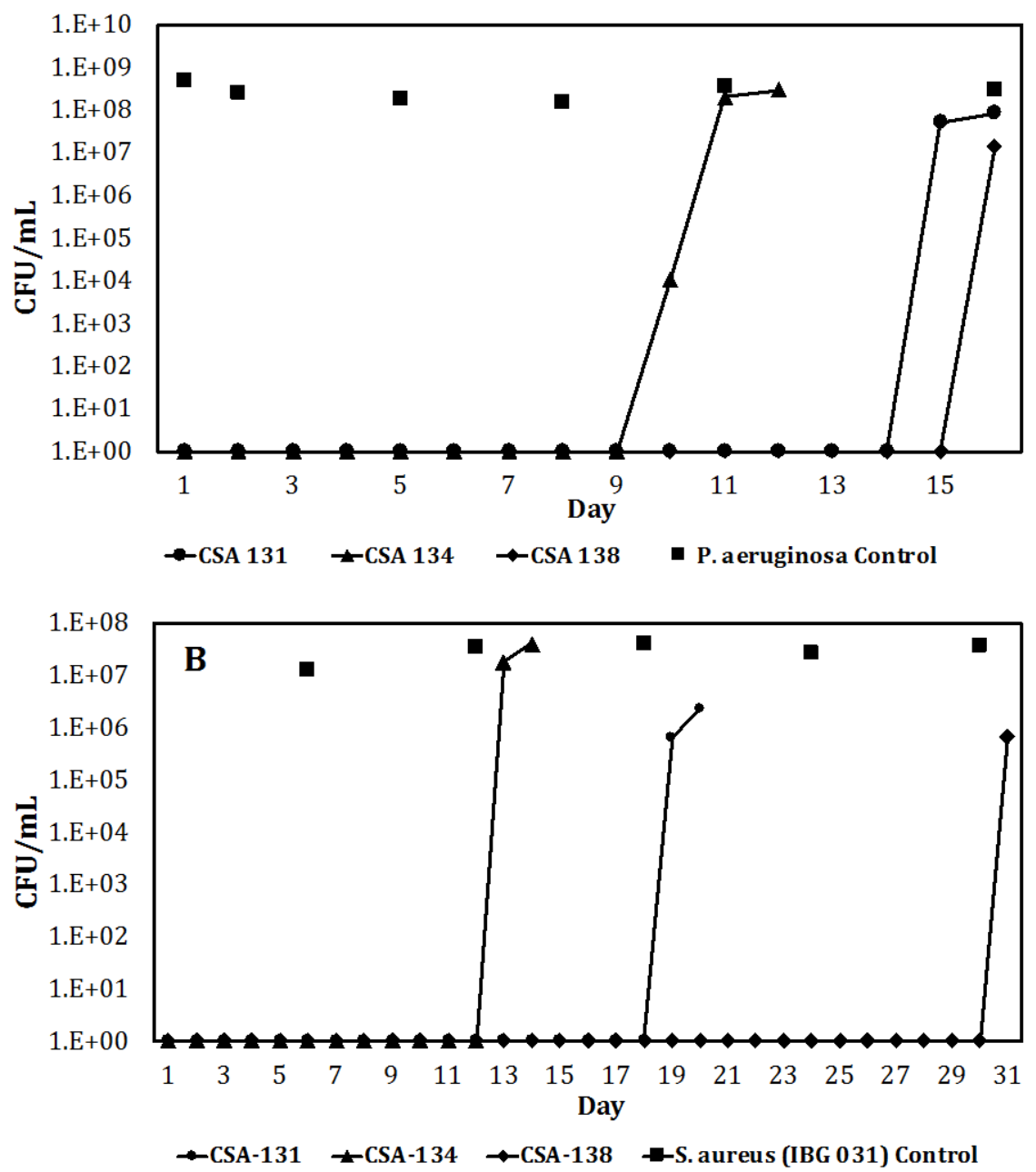

Figure 6. Bacterial population in nutrient media after $24 \mathrm{~h}$ incubation. Inoculated with P. aeruginosa ATCC 27853 (A), inoculated with S. aureus IBG 031 (B). Control lenses do not include any ceragenins. Lenses contained $1 \%$ of selected ceragenins, relative to the dry weight of the lens. Every $24 \mathrm{~h}$ lenses were placed in fresh media and reinoculated.

\subsubsection{Implanted medical device coatings}

Implant-related infections affect thousands of patients each year [120], and active-release antimicrobial coatings have been designed in order to combat this issue. These coatings release antimicrobial agents into the surrounding 
tissue and fluids with the intent of preventing biofilm formation on the device and infection at the implant site [121,122]. However, due to the presence of sessile organisms, if a biofilm forms on a device or the device is implanted in the presence of an established biofilm, most conventional antibiotics cannot fully protect implanted devices. An active-release coating containing ceragenins is an attractive option because ceragenins exhibit antibacterial activity against established biofilms, they do not lose effect in the presence of proteases and other enzymes, and they are easily incorporated into stable polymer coatings.

An active-release coating containing CSA-13 was first developed and described by Williams etal. [123] on fracture fixation plates. Investigation of the polymerization of a silicone coating showed that the incorporation of CSA-13 in particulate form $(18 \% \mathrm{w} / \mathrm{w})$ had no impact on the physical properties of the coating and SEM observation revealed that the CSA-13 was distributed evenly throughout the coating. Of critical importance, when placed in aqueous solution, CSA-13 eluted from the coating over a span of 30 days. Furthermore, thermal stability testing of the coating demonstrated that coated fixation plates retained stability at elevated temperatures, providing further evidence that the CSA-13-silicone combination would be a viable option for the coating of implanted devices $[121,124]$. In order to evaluate this coating in vivo, biofilms of methicillin-resistant $S$. aureus (MRSA) were grown on a polymer mesh. After being allowed to reach population densities of over $10^{9} \mathrm{CFU} \mathrm{cm}^{-2}$, the mesh was implanted on the tibia of sheep and then immediately covered with a fracture fixation plate that was coated with CSA-13-silicone. Following inoculation, each sheep in the control group developed infection, while those that received fixation plates coated with CSA-13 were fully protected from developing infection over the course of the 12-week study. Investigation of the surrounding tissue showed that the coating was well tolerated, with no evidence of cytotoxicity or inhibition of wound healing. Remarkably, it was noted that there was an increase in bone healing in the presence of ceragenin.

The ability of this coating to prevent infection caused by planktonic bacteria was also evaluated in vitro and in vivo $[125,126]$. The coating was applied to porous titanium plug implants and placed in mouse models infected with MRSA. While control mice had to be euthanized per protocol shortly after the start of the experiment due to effects of infection, mice with CSA-13 coated implants were protected from infection for the duration of the 12-week study. Furthermore, CSA-13 released from implants did not damage skeletal attachment sites of the titanium plug implant compared to controls. Taken together, these in vivo studies provide evidence that ceragenin-containing coatings can provide an effective antimicrobial function to implanted devices, allowing for the eradication of both planktonic and biofilm-associated bacteria. 


\subsubsection{Coated endotracheal tubes}

Endotracheal tubes (ETTs) are another medical device that offer pathogenic bacteria and fungi an abiotic surface on which to proliferate, and microbial colonization of ETTs is associated with ventilator associated pneumonia (VAP) and prolonged stays in intensive care [127]. Use of ETTs with an innate immune-like function is expected to reduce VAP and healthcare costs substantially. To provide such a function to ETTs, CSA-131 was incorporated into a medical-grade hydrogel and evaluated for prevention of microbial colonization of ETT surfaces [128]. A key aspect in the design of the coating was to develop means of controlling elution of CSA-131 and to allow ethylene oxide sterilization of the coating without reaction with the ceragenin. Hydrochloride salts of ceragenins are thermally stable, allowing sterilization via autoclaving necessary for contact lenses; however, the hydrochloride salts allow some degree of reaction with ethylene oxide. In contrast, naphthylene disulfonate salts of CSA-131 (CSA-131 NDSA) were shown to be inert to ethylene oxide sterilization. Furthermore, the limited solubility of CSA131NDSA provided a mechanism for controlled release from a hydrogel coating. Coatings were prepared with a milled form of CSA-131NDSA (submicron particle size) with coating thickness of 10 microns.

Coated ETTs were tested with daily inoculations of MRSA, P. aeruginosa, K. pneumoniae, $C$. albican, and $C$. auris, and coated tube segments remained uncolonized for up to 16 days (Figure 7). Coated ETTs were also effective against mixed-species inoculations, preventing biofilm formation for up to 4 days when inoculated with combinations of MRSA and $P$. aeruginosa or $P$. aeruginosa and $C$. auris. The surfaces of coated and uncoated ETT segments were visualized via SEM and showed no biofilm of mixed species of MRSA and PA01 or C. auris and PA01 after $48 \mathrm{~h}$, whereas uncoated ETT segments were heavily colonized (Figure 8). To demonstrate the safety of coated ETTs, a pig intubation model was utilized. Pigs treated with coated ETTs showed no significant difference in tracheal or laryngeal inflammation and cilia loss was not significantly different between tests and controls. The coated ETTs also resulted in no systemic exposure of pigs to ceragenins as no CSA-131 was found in the blood with a detection limit of $5 \mu \mathrm{g} \mathrm{mL} \mathrm{L}^{-1}$. The broad-spectrum activity of CSA-131 mimics that of AMPs and the hydrogel in which CSA131NDSA is imbedded on coated ETTs provides a sustained release of the ceragenin. This system appears well suited for clinical use in preventing VAP in intubated patients [128]. 

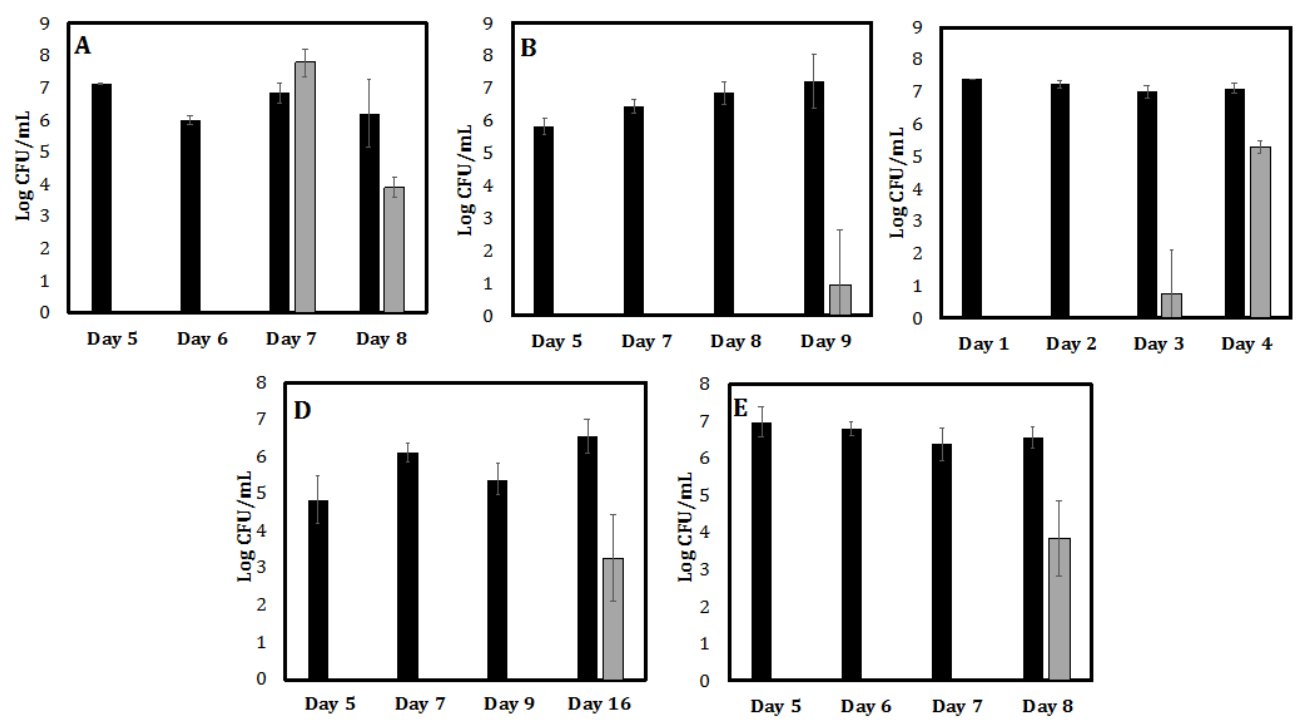

Figure 7. Biofilms formed on uncoated (black bar) and coated (gray bar) tubes after the indicated number of incubation days. MRSA BAA-41 (A), K. pneumoniae ATCC 13883 (B), P. aeruginosa ATCC 47085 (C), C. albicans ATCC 90028 (D), C. auris CDC $0383(\mathrm{E})$.
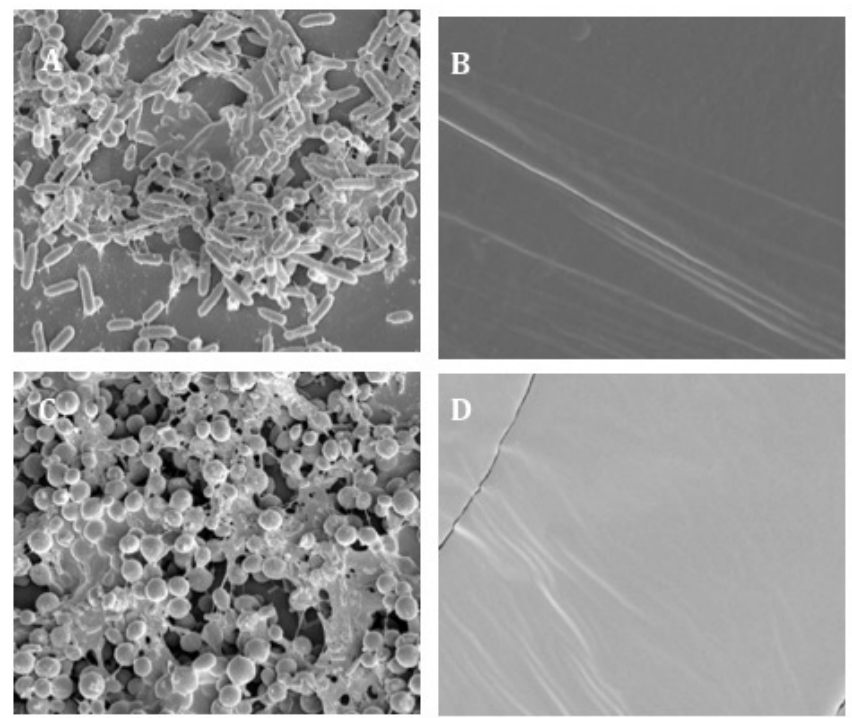

Figure 8. SEM images of biofilm of mixed species of MRSA and PA01 on an uncoated (A) and coated tube (B), biofilm of mixed species of PA01 and C. auris on an uncoated (C) and coated (D) tube after $48 \mathrm{~h}$. 


\subsubsection{Bone fractures}

Aside from their antimicrobial properties, AMPs have been shown to influence bone healing [129]. Considering this observation, the abilities of ceragenins to impact bone growth were determined. Selected ceragenins were tested in a rat femur-based model of bone regrowth to determine whether they would accelerate bone regrowth when used alone or in combination with bone morphogenic protein-2 (BMP-2), which is used clinically to accelerate bone regrowth. Of the ceragenins that were tested, CSA-90 displayed the most potent activity [130]. To determine if CSA-90 could positively impact bone regrowth while providing antibacterial protection of bone injury, a model of bone regrowth, complicated with infection, was used in a similar rat femurbased study. As anticipated, CSA-90 functioned to both prevent infection and potentiate the activity of BMP-2 in repairing and regrowing bone. In contrast, untreated rats had to be sacrificed per protocol within two weeks of fracture due to declining health. Because open fractures are very often complicated by infection, most often due to pathogens that dwell on the skin including $S$. aureus, the ability of ceragenins to both aid in bone regrowth while also serving to prevent infection at the fracture site could provide profound benefit to patients.

\subsubsection{Imaging infections}

AMPs and ceragenins display affinity toward bacterial membranes, and efforts have been made to leverage this property into selective association of AMPs or ceragenins, labeled with imaging agents, for use in imaging bacterial infections $[131,132]$. As further evidence of the affinity of ceragenins for bacterial membranes, CSA-124 was covalently attached to nanoparticles consisting of a silver shell with a maghemite core [114]. Imaging of the nanoparticles confirmed selective association with intact bacteria, with particular affinity for S. aureus. In vitro MRI studies further verified that these nanoparticles were able to adhere to $S$. aureus, indicating their potential to be used as contrast agents for use in imaging deep tissue infections [133].

Technicium (99mTc)-labeling of CSA-13 was also investigated as a means of imaging infections in mice. CSA-13 was chosen specifically because its multiple amine groups allow it to form stable complexes with the metal ion. Following direct infection of the thigh muscle in mice with $S$. aureus, the CSA-13-99mTc complex was administered. Imaging showed that the complex accumulated at the infection site and also in the kidneys [134]. Further efforts were made to alter the binding between the ceragenin and the technicium in order to allow the amine groups to remain free and available to form ionic interactions with bacterial membranes [135]. This modified complex has been shown to associate with $S$. aureus in in vitro studies. 


\subsubsection{Gastrointestinal diseases}

Helicobacter pylori is carried by about half of the world's adult population. While carriers are often asymptomatic, infection can lead to severe ulceration and gastritis, and is associated with gastric adenocarcinoma. The emerging threat of antibiotic-resistant strains led Leszczynska et al. [136] to test whether ceragenins could be used as a viable treatment option. They found that CSA-13 displayed significantly lower minimum bactericidal concentrations (MBC) against a variety of $H$. pylori clinical isolates as compared to LL-37. Furthermore, under simulated gastric conditions in the presence of low $\mathrm{pH}$ and pepsin, CSA-13 retained its bactericidal activity while the activity of LL-37 was lost. Interestingly, $H$. pylori, with its unique defense mechanisms of incorporating host cholesterol into it membrane and activity through its HefC efflux pump, showed some resistance to ceragenins, which was based on the presence of cholesterol in the bacterial membrane [137].

The impact of CSA-13 in gastrointestinal infections caused by Clostridium difficile has been studied in a mouse model [138]. Oral administration of an active formulation of CSA-13 containing Eudragit and methylcellulose resulted in CSA-13 release in the terminal ileum and colon where the environmental $\mathrm{pH}$ is alkaline. The inhibition of $C$. difficile spore germination and cell viability by CSA-13 was measured at $4 \mu \mathrm{g} \mathrm{mL}^{-1}$. Both subcutaneous and oral administration of CSA-13 decreased the concentration of $C$. difficile in fecal samples of mice, however Peptostreptococcaceae bacteria abundance increased suggesting that CSA-13 suppresses C. difficile via modulation of intestinal microbiota. Therefore, other microbial species and the balance of the gut microbiota should be considered with regard to further therapeutic application of CSA-13 in gastrointestinal diseases. According to the observations from this study, the protective action of CSA-13 could be generated through the direct suppression of C. difficile, by lowering the levels of pro-inflammatory metabolites (endocannabinoids), or by increasing the levels of protective metabolites (citrulline, 3 aminoisobutyric acid, retinol, and ursodeoxycholic acid) in the intestine [138].

\subsection{CONCLUSIONS}

The central and critical roles that AMPs play in innate immunity have been well documented and include broad-spectrum antimicrobial activities, the ability to sequester microbial endotoxins and thereby inhibit inflammatory processes and additional activities that accelerate wound healing. Recognition of these roles has led to intense research of AMPs; for example, thousands of papers have been published describing activities of the human cathelicidin LL-37. The potential for therapeutic use of AMPs has also been well 
recognized; however, issues related to clinical use have also emerged: "AMPs possess some limitations that hamper their clinical and commercial development such as high production costs, potential toxicity, susceptibility to proteases (also in the wound fluid), and unknown pharmacokinetics" [139]. By abandoning peptide structure, while retaining overall morphology, ceragenins provide a means of reproducing the beneficial properties of AMPs without incurring many of the issues hampering clinical use of AMPs.

Current studies with ceragenins have focused on applications in tissues that express relatively high amounts of AMPs, and ceragenins have proven to be well tolerated in these tissues. However, less work has been done with potential systemic exposure to ceragenins. Use of ceragenins in coatings of medical devices and at bone fractures could lead to wider exposure, but no adverse events have been observed. Intraperitoneal injection of CSA-13 into mice in an infection model showed efficacy without measured toxicity [140]. The possibility of systemic use of ceragenins exists, but the membranetargeting activity of ceragenins argues that their most attractive uses will be in localized applications. With successful demonstration of efficacy in vitro in multiple animal models, it is anticipated that ceragenins will continue development toward clinical use and eventual applications in replacing or augmenting the activities of endogenous AMPs. 


\section{REFERENCES}

1. G. Diamond, N. Beckloff, Curr. Pharm. Des. 15 (2009) 2377-2392.

2. T. Ebenhan, O. Gheysens, BioMed Res. Int. 2014 (2014) 867381.

3. T. Ganz, Integr. Comp. Biol. 43 (2003) 300-304.

4. $\quad$ M. Zasloff, Nature 415 (2002) 389-395.

5. F.W. Diggins, Br. J. Biomed. Sci. 56 (1999) 83-93.

6. M.M. Hashemi, M. Aminlari, LWT - Food Sci. Technol. 57 (2014) 594-602.

7. $\quad$ L. Aminlari, M.M. Hashemi, J. Food Sci. 79 (2014) R1077-R1090.

8. M.M. Hashemi, M. Aminlari, Pol J Food Nutr Sci. 68 (2017) 33-43.

9. L.-J. Zhang, R.L. Gallo, Curr. Biol. 26 (2016) R14-R19.

10. Y.-J. Jung, K.-K. Kang, Plant Breeding Biotechnol. 2 (2014) 1-13.

11. H. Soyeurt, F.G. Colinet, J Dairy Sci. 90 (2007) 4443-4450.

12. A. Giacometti, O. Cirioni, Peptides 24 (2003) 1315-1318.

13. A.A. Bahar, D. Ren, Pharmaceuticals 6 (2013) 1543-1575.

14. M. Zasloff, Proc. Natl. Acad. Sci. 84 (1987) 5449-5453.

15. S.-K. Choi, S.-Y, Park, J. Bacteriol. 191 (2009) 3350-3358.

16. L. Xu, H. Huang, BMC Genomics 15 (2014) 363-381.

17. C.S. Daphny, M.A. Bibiana, J. Pharm. Sci. Res. 7 (2015) 226-230.

18. L.T. Nguyen, E.F. Haney, Trends Biotechnol. 29 (2011) 464-472.

19. J.A. Patch, A.E. Barron, J. Am. Chem. Soc. 125 (2003) 12092-12093.

20. J. Johansson, G.H. Gudmundsson, J. Biol. Chem. 273 (1998), 3718-3724.

21. R.I. Lehrer, C.L. Bevins, in Mucosal Immunol., Academic Press, New York, USA, 2005, 95.

22. B. Mojsoska, H. Jenssen, Pharmaceuticals 8 (2015) 366-415.

23. M. Hartmann, M. Berditsch, Antimicrob. Agents Chemother. 54 (2010) 31323142.

24. Y. Rosenfeld, Y. Shai, Biochim. Biophys. Acta 1758 (2006) 1513-1522.

25. B. Ding, Q. Guan, J. Med. Chem. 45(2002) 663-669.

26. H. Sato, J.B. Feix, Biochim. Biophys. Acta. 1758 (2006), 1245-1256.

27. T. Ganz, R.I. Lehrer, Curr. Opin. Immunol. 10 (1998) 41-44.

28. J.M. Loeffler, D. Nelson, Science 294 (2001) 2170-2172.

29. H. Jenssen, P. Hamill, Clin. Microbiol. Rev. 19 (2006) 491-511.

30. M.L. Mangoni, A.M. McDermott, Exp. Dermatol. 25 (2016) 167-173.

31. J.D. Heilborn, M.F. Nilsson, J. Invest. Dermatol. 120 (2003) 379-389.

32. R.M. Epand, R.F. Epand, Drug News Perspect. 21 (2008) 307-311.

33. Q. Guan, L. Chunhong, Org. Lett. 2 (2000) 2837-2840.

34. P.B. Savage, C. Li, Expert Opin. Investig. Drugs 9 (2000) 263-272.

35. C. Li, M.R. Lewis, Antimicrob. Agents Chemother. 43 (1999) 1347-1349.

36. A. Kichler, C. Leborgne, J. Control. Release 107 (2005) 174-182.

37. E. Isogai, H. Isogai, Oral Microbiol. Immunol. 24 (2009) 170-172.

38. M.M. Hashemi, B.S. Holden, J Antimicrob. Agents 3 (2017) 1000141.

39. U. Surel, K. Niemirowicz, Studia Medyczne 30 (2014) 207-213.

40. C. Li, A.S. Peters, J. Am. Chem. Soc. 120 (1998) 2961-2962.

41. B. Ding, U. Taotofa, Org. Lett. 6 (2004) 3433-3436.

42. P.B. Savage, C. Li, FEMS Microbiol. Lett. 217 (2002) 1-7.

43. C. Li, N.K. Dalley, Tetrahedron Lett. 40 (1999) 1861-1864.

44. X.-Z. Lai, Y. Feng, Acc. Chem. Res. 41 (2008) 1233-1240.

45. E.J. Schmidt, J.S. Boswell, J. Antimicrob. Chemother. 47 (2001) 671-674. 
46. X.-T. Zhou, A.U. Rehman, Org. Lett. 2 (2000) 3015-3018.

47. U. Taotafa, D.B. McMullin, Org. Lett. 2 (2000) 4117-4120.

48. P.B. Savage, Curr. Med. Chem.-Anti-Infect. Agents 1 (2002) 293-304.

49. P.B. Savage, Ann. Med. 33 (2001) 167-171.

50. W.C. Wimley, ACS Chem. Biol. 5 (2010) 905-917.

51. R. Bucki, P.G. Georges, Biochemistry 44 (2005) 9590-9597.

52. R. Bucki, A.G. Sostarecz, J. Antimicrob. Chemother. 60 (2007) 535-545.

53. H.R. Chileveru, S.A. Lim, Biochemistry 54 (2015) 1767-1777.

54. H. Choi, N. Rangarajan, Trends Microbiol 24 (2016) 111-122.

55. M. Meincken, D.L. Holroyd, Antimicrob. Agents Chemother. 49 (2005) 40854092.

56. B. Ding, N. Yin, J. Am. Chem. Soc. 126 (2004) 13642-13648.

57. K. Pogoda, E. Piktel, Micron 101 (2017) 95-102.

58. M.D. Howell, J.E. Streib, J. Invest. Dermatol. 129 (2009) 2668-2675.

59. U. Wnorowska, K. Niemirowicz, Antimicrob. Agents Chemother. 59 (2015) 3808-3815.

60. J.N. Chin, M.J. Rybak, Antimicrob. Agents Chemother. 51 (2007)1268-1273.

61. C. Bozkurt-Guzel, P.B. Savage, BioMed. Res. Int. 2014 (2014) 710273.

62. Y.H. Cheng, T.L. Lin, Agents Chemother. 59 (2015) 2909-2913.

63. M.M. Hashemi, J. Rovig, Antimicrob. Agents Chemother. 61 (2017) 0029200217.

64. K. Leszczyńska, D. Namiot, J. Antimicrob. Chemother. 68 (2013) 610-618.

65. S. Saha, P.B. Savage, J. Appl. Microb. 105 (2008) 822-828.

66. C. Li, L.P. Budge, J. Am. Chem. Soc. 121 (1999) 931-940.

67. C. Bozkurt-Guzel, P.B. Savage, Chemotherapy 57 (2012) 505-510.

68. J.N. Chin, R.N. Jones, J. Antimicrob. Chemother. 61 (2008) 365-370.

69. K. Leszczyńska, A. Namiot, J. Appl. Microbiol. 110 (2011) 229-238.

70. M. Zhang, W. Chang, FEMS Yeast Res. 18 (2018) foy002.

71. B. Durnaś, U. Wnorowska, PloS One 11 (2016) e0157242.

72. E. Larkin, C. Hager, Antimicrob. Agents Chemother. 61 (2017) AAC02396-16.

73. S.M. Rudramurthy, A. Chakrabarti, J. Antimicrob. Chemother. 72 (2017) 17941801.

74. M.M. Hashemi, J. Rovig, J. Antimicrob. Chemother. (2018). doi: 10.1093/jac/dky085.

75. P.-W. Tsai, Y.-L. Cheng, J. Microbiol. 52 (2014) 581-589.

76. H. Lee, J.-S. Hwang, Biochem. J. 474 (2017) 635-645.

77. J. Lee, D.G. Lee, FEMS Microbiol. Lett. 355 (2014) 36-42.

78. J.H. Wong, T.B. Ng, Peptides 32 (2011) 1996-2002.

79. K. Niemirowicz, B. Durnas, Sci. Rep. 7 (2017) 4610.

80. M.E. Davey, G.A. O'Toole, Microbiol. Mol. Biol. Rev. 64 (2000) 847-867.

81. S.L. Percival, L. Suleman, J. Med. Microbiol. 64 (2015) 323-334.

82. M.A. Kohanski, D.J. Dwyer, Nat. Rev. Microbiol. 8 (2010) 423-435.

83. M. Olekson, T. You, FEBS Open Bio, 7 (2017) 953-967.

84. J. Pollard, J. Wright, Anti-Infect. Agents Med. Chem. 8 (2009) 290-294.

85. C. Nagant, Y. Feng, J. Appl. Microbiol. 111 (2011) 763-772.

86. C. Nagant, B. Pitts, Microbiologyopen 2 (2013) 318-325.

87. E. Piktel, K. Pogoda, Future Med. 12 (2017) 735-737.

88. I.S. Tan, K.S. Ramamurthi, Environ. Microbiol. Rep. 6 (2014) 212-225.

89. E. Piktel, K. Pogoda, Sci. Rep. 7 (2017) 44452. 
90. B. Yasin, W. Wang, J. Virol. 78 (2004) 5147-5156.

91. Y. Park, S.H. Jang, J. Peptide Sci. 10 (2004) 304-311.

92. D. Lara, Y. Feng, J. Parasitol. 96 (2010) 638-642.

93. J.Y. Niederkorn, H, Alizadeh, Microbes Infect. 1 (1999) 437-443.

94. Z.A. Polat, P.B. Savage, J. Ocul. Pharmacol. Ther. 27 (2011) 1-5.

95. A.A. Polat, A. Cetin, Acta Parasitol. 61 (2016) 376-381.

96. A. Peschel, H.-G. Sahl, Nat. Rev. Microbiol. 4 (2006) 529-536.

97. M.L. Mangoni, A.M. McDermott, Exp. Dermatol. 25 (2016) 167-173.

98. S.C. Nang, F.C. Morris, J. Antimicrob. Chemother. (2018) doi:10.1093/jac/dky061.

99. S. Matamouros, S.I. Miller, Biochim. Biophys. Acta (BBA) - Biomembranes 1848 (2015) 3021-3025.

100. E. Llobet, V. Martinez-Moliner, Proc. Natl. Acad. Sci. USA. 112 (2015) E63696378.

101. L. Poirel, A. Jayol, J. Antimicrob. Chemother. 70 (2015) 75-80.

102. J.-Y. Lee, K.S. Ko, Diagn. Microbiol. Infect. Dis. 78 (2014) 271-276.

103. J.E. Pollard, J. Snarr, J. Antimicrob. Chemother. 67 (2012) 2665-2672.

104. R. Bucki, D.B. Namiot, J. Antimicrob. Chemother. 62 (2008) 329-335.

105. R. Bucki, B. Durnas, Infect. Drug Resist, 11 (2018) 77-86.

106. M. Moscoso, M. Esteban-Torres, PLoS One 9 (2014) e101037.

107. C. Nagant, M. Tre-Hardy, Appl. Microb. Biotechnol. 88 (2010) 251-263.

108. J.J. Escobar-Chávez, M. López-Cervantes, J. Pharm. Pharm. Sci. 9 (2006) 339358.

109. C. Nagant, P.B. Savage, J. Appl. Microbiol. 112 (2012) 1173-1183.

110. I.I. Wistuba, A.K. Virmani, J. Natl. Cancer Inst. 89 (1997) 1366-1373.

111. A.C. Schamberger, C.A. Staab-Weijnitz, Sci. Rep. 5 (2015) 8163.

112. S.F. Nunes, P.R. Murcia, Influenza Other Respi. Viruses 4 (2010) 7-15.

113. M.M. Hashemi, B.S. Holden, Molecules 23 (2018) 596-608.

114. M.A. Hoppens, C.B. Sylvester, ACS Appl. Mater. Interfaces 6 (2014) 1390013908.

115. K. Niemirowicz, U. Surel, J. Nanobiotechnol. 13 (2015) 1-11.

116. K. Niemirowicz, E. Piktel, Int. J. Nanomed. 11 (2016) 5443-5455.

117. B. Durnaś, E. Piktel, BMC Microbiol. 17 (2017) 167-178.

118. L.B. Szczotka-Flynn, E. Pearlman, Eye Contact Lens 36 (2010) 116-129.

119. X. Gu, J.D. Jennings, Invest. Ophthalmol. Vis. Sci. 54 (2013) 6217-6223.

120. R.O. Darouiche, N. Engl. J. Med. 350 (2004) 1422-1429.

121. E.M. Hetrick, M.H.H. Schoenfisch, Chem. Soc. Rev. 35 (2006) 780-789.

122. J.W. Costerton, Clin. Orthop. Relat. Res. 437 (2005) 7-11.

123. D.L.Williams, K.D. Sinclair, J. Biomed. Mater. Res. Part B: Appl. Biomat. 101 (2013) 1078-1089.

124. D.L. Williams, B.S. Hymond, Biomaterials 33 (2012) 8641-8656.

125. K.D. Sinclair, T.X. Pham, J. Biomed. Mater. Res. Part B: Appl. Biomater. 101 (2013) 1143-1153.

126. K.D. Sinclair, T.X. Pham, J. Biomed. Mater. Res. Part A 100 (2012) 2732-2738.

127. J. Rosenblatt, R. Reitzel, BioMed. Res. Int. 2014 (2014) 120468.

128. M.M. Hashemi, J. Rovig, J. Antimicrob. Chemother. 73 (2018) 143-150.

129. M.G. Scott, D.J. Davidson, J. Immunol. 169 (2002) 3883-3891.

130. A. Schindeler, Y.C. Nicole, J Bone Joint Surg. Am. 97 (2015) 302-309.

131. R.F. Epand, P.B. Savage, Biochim. Biophys. Acta 1768 (2007) 2500-2509. 
132. P. Nibbering, M.M. Welling, Nucl. Med. Commun. 19 (1998) 1117-1122.

133. M.A. Hoppens, Z.E.Wheeler, J. Colloid Interface Sci. 413 (2014) 167-174.

134. S. Roohi, N. Amir, Radiochim. Acta Int. J. Chemi. Asp. Nucl. Sci. Technol. 97 (2009) 57-62.

135. R. Zahoor, S. Roohi, J. Radioanal. Nucl. Chem. 295 (2013) 841-844.

136. K. Leszczynska, A. Namiot, BMC Microbiol. 9 (2009) 187-197.

137. E.A. Trainor, K.E. Horton, Infect. Immun. 79 (2011) 88-97.

138. J. Wang, S. Ghali, Gastroenterol. (2018) doi: 10.1053/j.gastro.2018.01.026.

139. A. Pfalzgraff, K. Brandenburg, Front Pharmacol. 9 (2018) 281-304.

140. R. Bucki, K. Niemirowicz, Antimicrob. Agents Chemother. 59 (2015) 62746282.

(C)2018 by the authors; licensee IAPC, Zagreb, Croatia. This chapter is an open-access publication distributed under the terms and conditions of the Creative Commons Attribution license (http://creativecommons.org/licenses/by/3.0/) (cc)) EY 